\title{
Molecular cloning of flounder Xp18, a newly identified highly conserved protein mainly expressed in the ovary
}

\author{
Jérôme Cachot ${ }^{\mathrm{a}}{ }^{\star}$, Florence Bultelle ${ }^{\mathrm{a}}$, Laurent Drouot $^{\mathrm{b}}$, François Galgani ${ }^{\mathrm{c}}$, Thierry Frébourg ${ }^{\mathrm{d}}$, \\ François Leboulenger ${ }^{a}$ and Jean-Michel Danger ${ }^{a}$
}

\author{
aLaboratory of Ecotoxicology, UPRES-EA 3222, IFRMP 23, University of Le Havre, 25 rue Philippe Lebon, BP \\ 540, 76058, Le Havre Cedex, France \\ 'INSERM U519, IFRMP 23, University of Rouen, 22 boulevard Gambetta, 76183, Rouen Cedex, France \\ IFREMER/DEL, bd. Jean Monnet, BP 171, 34200, Sète Cedex, France \\ 'Laboratory of Molecular Genetics, INSERM EMI 9906, IFRMP 23, University of Rouen, 22 boulevard Gambetta, \\ 76183, Rouen Cedex, France \\ *: Corresponding author : Tel.: +33-2-3274-4303; fax: +33-2-3274-4314 jerome.cachot@univ-lehavre.fr
}

\begin{abstract}
Screening of a flounder ovary cDNA library with a rainbow trout $p 53$ probe led to the isolation of a p53-unrelated cDNA encoding an unknown 161 amino acid protein. In view of its apparent molecular weight and yet unknown function, the deduced protein was named Xp18. Corresponding orthologous cDNAs or expressed sequence tags have been identified in several species including human, rodents, bovine, chicken and zebrafish and a related cDNA has also been isolated in the fruit fly. Deduced amino acid sequences appeared to be extremely well conserved throughout vertebrate evolution. Structure predictions suggested that Xp18 may correspond to an integral protein comprising four transmembrane domains. The charged C-termini of all known vertebrate Xp18-like proteins displayed a characteristic KXKXX motif which is considered as an endoplasmic reticulum targeting sequence. Gene expression, as shown by Northern blot and quantitative reverse transcription-polymerase chain reaction analysis, was significantly higher in the ovary and to a lesser extent in the brain. Xp18 transcripts were also detected by in situ hybridization in most of the circumventricular regions of the brain of adult flounders. The gene encoding the human protein is located on chromosome Xq22.1, a genome region involved in numerous genetic diseases including premature ovarian failure.
\end{abstract}

Keywords: Platichthys flesus; Teleostean; Human; Ovary; Brain; X chromosome 


\section{Introduction}

It is now well established that a variety of chemical compounds of anthropogenic origin, can induced long term effects on living organisms including cancers and reproductive defects. When acting on reproduction, pollutants can provoke chromosome abnormalities, reduce success of fertilization, decrease hatching or survival of larvae and can also interfere with hormonal regulations (reviewed in Janssen et al., 1995). In marine environment, these disorders mainly affect benthic fish living in coastal and estuarine areas near industrial and urban centers.

As an evidence, an histological survey of gonads of European flounder specimens conducted in the Seine river estuary (France) has shown that up to $8 \%$ of males were intersex e.g. had testes characterized by the presence of entire ovarian structures (Minier et al., 2000).

The European flounder, Platichthys flesus (L.), is a model species for pollution monitoring in the north eastern Atlantic. This euryhaline flatfish lives on and in the sediment of coastal waters and estuaries resulting in a strong exposure to river-carried pollutants. In addition, this species seems particularly sensitive to several chemical-induced and infectious diseases (Vethaak and Jol, 1996).

In the Seine estuary, sexual differentiation of European flounders is initiated during their second year of life. At this age, gametogenesis begins since early perinucleolus oocytes are continuously produced and gradually accumulate during a year. Development of oocytes takes place the next year when they enter vitellogenesis and start the maturation process (Janssen et al., 1995). Sexually mature flounders then migrate in January and February to shallow coastal areas for spawning. The annual ovarian cycle ends with the degeneration of post-ovulatory follicles in post-spawning female.

Our purpose was initially to identify $p 53$-related genes in this fish species in order to study the molecular basis of carcinogenesis in fish and also to develop new markers for mutation and cancer risk assessment in marine ecosystems. A flounder ovary cDNA library was constructed and screened under low stringency conditions using a rainbow trout p53 cDNA probe. Two positive cDNA clones were isolated, one of which did correspond to the flounder p53 cDNA (Cachot et al., 1998). Sequencing of the second clone revealed that the cDNA sequence displayed only $35 \%$ homology with trout $\mathrm{p} 53$. However, in silico screening of genome data bases indicated that this novel cDNA had striking homologies with an unknown cDNA which has recently been identified in human embryos (Isogai et al. 2000). In the present paper we describe the molecular cloning and the expression profile of this novel cDNA which was named Xp18.

\section{Materials and Methods}

\subsection{Cloning of flounder Xp18}

A flounder ovary cDNA library previously constructed in Lambda ZAP $^{\circledR}$ II vector (Cachot et al., 1998) was screened at low stringency with the complete rainbow trout p53 cDNA. The probe was radiolabeled with $\left(\alpha^{32} \mathrm{P}\right)$-dCTP (Amersham) using a random priming kit (Ready-to-Go, Pharmacia). Hybridization was performed overnight at $55^{\circ} \mathrm{C}$ in $6 \mathrm{x} \mathrm{SSC}(0.9$ $\mathrm{M} \mathrm{NaCl}, 0.09 \mathrm{M}$ sodium citrate), 4x Denhardt's reagent, $0.5 \%$ SDS, 2mM EDTA and 1ng. $\mathrm{mL}^{-1}$ of radiolabeled probe. The membrane were washed in 4x SSC, $0.5 \%$ SDS for 1 hour at $55^{\circ} \mathrm{C}$ before a $24 \mathrm{hr}$-exposition to X-ray film (Kodak X-Omat). After five rounds of screening, positive plaques were isolated and inserts subcloned into pBluescript SK(-) vector according to the protocol of the manufacturer (Clontech). Both DNA strands were sequenced on a 373A DNA sequencer according to the Big Dye Terminator procedure (Perkin Elmer). 


\subsection{Northern blot analysis}

Flounders were collected in the Seine bay and anaesthetized in MS222 before tissue collection. Total RNAs were extracted from brain, liver, spleen, intestine, muscle, ovary and testis of adult flounder by using the TRI Reagent ${ }^{\mathrm{TM}}$ protocol (Sigma). The total RNAs $(20 \mu \mathrm{g})$ were separated on a $0.8 \%$ formaldehyde-agarose denaturing gel and then blotted onto a nylon membrane (Amersham Hybond-N+). A 1300 bp fragment generated by EcoRI digestion of the flounder $X p 18$ cDNA was used as a probe. This DNA was labeled with $\left(\alpha^{32} \mathrm{P}\right)$-dCTP (Amersham) using a random priming DNA labeling kit (Prime-a-gene, Promega). Hybridization was performed for 16 hours at $42^{\circ} \mathrm{C}$ in $5 x \operatorname{SSPE}(0.75 \mathrm{M} \mathrm{NaCl}, 0.05 \mathrm{M}$ $\mathrm{NaH}_{2} \mathrm{PO}_{4}, 5 \mathrm{mM}$ EDTA) $50 \%$ deionized formamide, 1\% SDS, 5x Denhardt's reagent, 5\% dextran sulfate, $100 \mu \mathrm{g} \cdot \mathrm{mL}^{-1}$ of denatured salmon sperm DNA and $1 \mathrm{ng} \cdot \mathrm{mL}^{-1}$ of radiolabeled probe. The membrane was then washed for 1 hour at $65^{\circ} \mathrm{C}$ in $2 \mathrm{x}$ SSPE- $0.1 \%$ SDS and exposed at $-80^{\circ} \mathrm{C}$ to $\mathrm{X}$-ray films (Kodak X-Omat) for 1 week.

\subsection{Real-time quantitative RT-PCR}

Total RNAs were extracted with TRI Reagent ${ }^{\mathrm{TM}}$ (Sigma) from ten tissues of adult flounders. RNA quality was checked on denaturating agarose gel before used. First strand cDNA synthesis was performed using Rnase free Superscript II (Invitrogen) from $5 \mu \mathrm{g}$ total RNAs in a $20 \mu \mathrm{L}$ reaction mixture containing $500 \mathrm{ng}$ oligo(dT) ${ }_{15}$ (Genset), $10 \mathrm{nmol} \mathrm{dNTP}$, $1 \mathrm{X}$ first strand buffer, $200 \mathrm{nmol}$ DTT for $50 \mathrm{~min}$ at $42^{\circ} \mathrm{C}$. The obtained cDNAs were purified on QIAquick PCR purification kit (Qiagen) and eluted with $30 \mu \mathrm{L}$ of Tris- $\mathrm{HCl} 10 \mathrm{mM}, \mathrm{pH}$ 8.5 .

PCR amplifications were performed using FirstStart DNA Master SYBR Green I and the LightCycler system (Roche Molecular Biochemicals) with $0.5 \mu \mathrm{M}$ of each primers, $4 \mathrm{mM}$ $\mathrm{MgCl}_{2}$ and $2 \mu \mathrm{L}$ of purified cDNA template. Forward (5'ACCGACAGACGCTCATCCAGT-3') and reverse (5'TGACCAGCAGCAGCAAAAAGTT-3') primers for Xp18 were carefully selected in two neighbouring exons using PrimerPremier3 software (Premier Biosoft International) in order to obtain a unique amplicon of $359 \mathrm{bp}$. The cycling conditions were as follows : initial denaturation at $95^{\circ} \mathrm{C}$ for 5 min followed by 40 cycles at $95^{\circ} \mathrm{C}$ for $15 \mathrm{~s}, 58^{\circ} \mathrm{C}$ for $5 \mathrm{~s}$ and $72^{\circ} \mathrm{C}$ for $14 \mathrm{~s}$. The level of the housekeeping gene $\beta$-actin was used to normalize for the variability of RNA quality and quantity as well as for differences in the efficiencies of the RT-reactions. Forward (5'-TCCTGACCCTGAAGTACCCC-3') and reverse (5'GGTGCCCATCTCCTGCTCGA-3') primers for $\beta$-actin were carefully selected in two neighbouring exons (Lee et al., 2000) using PrimerPremier3 software in order to obtain a unique amplicon of $496 \mathrm{bp}$. The cycling conditions were identical as for Xp18 except for the hybridization temperature $\left(53^{\circ} \mathrm{C}\right)$ and the extension time $(20 \mathrm{~s})$. The levels of $X p 18$ and $\beta$ actin cDNAs were obtained from the same RT reaction. All samples were analysed in duplicate. For each experiment a standard curve was performed using a ten-fold serial dilution of cloned Xp18 or $\beta$-actin cDNA (Fig. 4). The amplification efficiencies were calculated from the slope of the standard curves using the equation $\mathrm{E}=10^{-1 / \text { slope }}$ and was always greater than 1.92 (96\%). Specificity of PCR amplification was checked using both melting curve analysis and agarose gel electrophoresis of PCR products.

Results are reported as the ratio of Xp18 to $\beta$-actin number of copies of mRNA. Copy numbers were calculated from the standard curve obtained for each experiment. 


\subsection{In situ hybridization}

Briefly, a 510-bp fragment of Xp18 cDNA was amplified by PCR (sense, 5'GCAAGCCCCGGTCCAGAAAC-3' and antisense primer, 5'-GATCTTAGGACTGCTT-3') and was subcloned into pGEM-T vector (Promega). Single stranded sense and antisense Xp18 RNA probes were generated following digestion with either PstI or SacII by using a Promega riboprobe kit and $\left(\alpha^{33} \mathrm{P}\right)$-UTP as a label. RNA probes were purified by Sephadex G-50 gel chromatography (elution buffer; $10 \mathrm{mM}$ Tris-HCl, $\mathrm{pH}$ 7.5, 0.1\% SDS). Fish were anaesthetized in MS222 and perfused transcardially with 4\% paraformaldehyde in phosphate buffer $(0.1 \mathrm{M}, \mathrm{pH} 7.4)$. The tissues were postfixed for $3 \mathrm{hr}$ at $4^{\circ} \mathrm{C}$ in the same solution, transferred into $0.1 \mathrm{M}$ phosphate buffer containing $15 \%$ saccharose for $12 \mathrm{hr}$ and frozen in isopentane at $-30^{\circ} \mathrm{C}$. Sections $(15 \mu \mathrm{m}$ thick) were cut in a cryomicrotome (2800 Frigocut, Leica, Heidelberg, Germany) and collected on $0.5 \%$ gelatin $/ 0.05 \%$ chrome alum $/ 0.01 \%$ polylysine coated slides. Tissue sections were incubated in phosphate buffer saline (PBS; 140 $\mathrm{mM} \mathrm{NaCl}, 2.7 \mathrm{mM} \mathrm{KCl}, 10 \mathrm{mM}, \mathrm{Na}_{2} \mathrm{HPO}_{4}, 1.8 \mathrm{mM} \mathrm{KH_{2 }} \mathrm{PO}_{4}$ ), treated in PBS containing $0.3 \%$ Triton $\mathrm{X}-100$ for $15 \mathrm{~min}$ and permeabilized for $30 \mathrm{~min}$ in TE buffer ( $100 \mathrm{mM}$ Tris-HCl, $50 \mathrm{mM}$ EDTA, pH 8.0) containing $1 \mu \mathrm{g} \cdot \mathrm{mL}^{-1}$ proteinase K. Sections were then postfixed for 5 min at $4{ }^{\circ} \mathrm{C}$ in PBS containing 4\% paraformaldehyde. Acetylation was carried out for $10 \mathrm{~min}$ in $0.1 \mathrm{M}$ triethanolamine buffer $\mathrm{pH} 8.0,0.25 \%$ acetic anhydride. The slides were rinsed in $2 \mathrm{x}$ SSC, and covered with prehybridization buffer (4x SSC containing $50 \%$ deionized formamide). Hybridization was performed under a coverslip overnight at $37^{\circ} \mathrm{C}$ in $40 \%$ deionized formamide, $10 \%$ dextran sulfate, $1 \mathrm{x}$ Denhardt's solution, $4 \mathrm{x}$ SSC, $10 \mathrm{mM}$ dithiothreitol, $1 \mathrm{mg} / \mathrm{ml}$ denatured Salmon sperm DNA containing the purified antisense or sense Xp18 RNA probe. Slides were then washed twice in $2 x \mathrm{SSC}$ at $37^{\circ} \mathrm{C}$. A series of 4 washes was performed at $37^{\circ} \mathrm{C}$ in $0.1 \mathrm{x}$ SSC. The slides were finally dried in ethanol and exposed either onto films (BioMax MR, Kodak) for 2 weeks or overnight in a phosphoimager (Molecular Dynamics).

\subsection{Computer and statistical analyses}

Sequence analyses were performed by using the GCG package hosted by the server Infobiogen of INSERM-CNRS. Multiple alignments were carried out using ClustalW (Thompson et al., 1994). Homology searches were performed on the sequences listed in EMBL/GenBank/DDBJ databases with FASTA (Pearson and Lipman, 1988) and BLAST (Altschul et al., 1990).

Statistical analysis of $X p 18$ to $\beta$-actin mRNA ratio in the ovary, brain and testis were determined by the unpaired two-tailed Student's $t$ test. Differences were considered statistically significant for $p<0.05$. Mean values are given with their standard deviation (SD).

\subsection{Nucleotide sequence accession number}

The EMBL accession number of flounder Xp18 cDNA is AJ302671.

\section{Results and Discussion}

\subsection{Cloning of flounder Xp18}

After five rounds of screening of the flounder cDNA library, two distinct positive clones were isolated. The longest clone contained an insert of $2279 \mathrm{bp}$ in length which corresponded 
to the cDNA encoding the p53 protein (Cachot et al., 1998). However, the $1682 \mathrm{bp}$ insert of the second clone had only $35 \%$ overall homology with trout $p 53$ cDNA. This insert included a 5 '-untranslated region of 90 nucleotides, followed by an open reading frame comprising 486 nucleotides (Fig. 1A). The 3'-untranslated sequence was $1.1 \mathrm{~kb}$ in length and contained two putative polyadenylation signals (nucleotides 677 and 1639) and a polyadenylated tail starting at nucleotide 1665 . The open reading frame encoded for a 161 amino acid protein with a molecular weight of 17,927 Da and a theoretical pI of 9.86. In view of its predicted molecular weight, and owing to its unknown function, the protein was coded Xp18. Composition analysis of Xp18 protein revealed a high number of leucine $(15.5 \%)$ and other hydrophobic residues $(37 \%)$ in comparison with charged amino acids $(25 \%)$. Charged residues were mostly clustered in two blocks, the first one encompassing residues 30 to 45 and the second one the last 30 or 35 residues of the C-terminus. Search in several motif databases revealed the presence of 2 putative protein kinase $\mathrm{C}$ and 2 casein kinase II phosphorylation sites as well as 2 putative N-myristoilation sites (Fig. 1A). The hydrophobicity plot (Kyte and Doolittle, 1982) revealed the existence of 4 hydrophobic domains spanning the amino-terminus and the major part of the core protein (Fig. 1B). In contrast, the 30 amino acids at the carboxyterminus appeared to be very hydrophilic. Structural prediction of membrane-bound proteins (Argos et al., 1982) suggested that the Xp18 protein was integrated in biological membranes and contained four transmembrane sections corresponding to the four hydrophobic domains. In addition, prediction of signal peptides and anchor signal by a hidden Markov model (Nielsen et al., 1997) indicated that the first transmembrane domain was likely to correspond to an anchorage region to the endoplasmic reticulum (ER) membrane. Calculation of secondary structures by the PHD network system (Rost and Sander, 1994) indicated the presence of three to four alpha helixes encompassing the four hydrophobic domains of the protein and separated by 2-3 loops. An additional alpha helix spanned the acidic carboxyterminus. The Xp18 protein contained a characteristic KXKXX motif. This motif is a KKXX related-signal which has been shown to function as an ER localization signal of integral membrane proteins with C-termini oriented on the cytoplasmic side of the membrane (Nilsson et al., 1987). The consensus sequence is recognized by the COPI complex which participates in the formation of coated budding vesicles. Coatomer binding to the C-terminal KKXX signal mediates retrieval of ER membrane proteins (Hong, 1996). These data indicate that Xp18 might correspond to an integral membrane protein of the ER which may be sorted to budding vesicles. 
-90 a a t t c g cggccgcg t cgaccgaccgacagacgct cat c cag t c cggtgagggaaagcgcc $-30 \mathrm{ctg}$ agc $\mathrm{g}$ c tg c a a g c c c gg t c c aga a a ATGGCTTCGCCGAGGACAGTCACCATCGTG $\begin{array}{lllllllllll} & \text { M } & \text { A } & \text { S } & \text { P } & \text { R } & \text { T } & \text { V } & \text { T } & \text { I } & \text { V } \\ 31 \text { GCCCTTTCCATCGCCCTGGGCCTGTTCTTCGTGTTCATGGGAACCATCAAACTCACACCG }\end{array}$ $\begin{array}{llllllllllllllllllllll}\text { A } & \text { L } & \text { S } & \text { I } & \text { A } & \text { L } & \text { G } & \text { L } & \text { F } & \text { F } & \text { V } & \text { F } & \text { M } & \text { G } & \text { T } & \text { I } & \text { K } & \text { L } & \text { T } & \text { P } & 30\end{array}$ Anchor
91 AGGCTCAGCAAAGACGCCTACAGTGAAATGAAAAGGGCCTACAAGAGTTACGCCAAGGCA

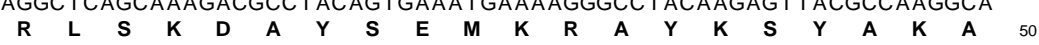
151 CTGCCGGGCCTGAAGAAGATCGgGATCAGCTCAGTCCTGCTCCGCAAGATCATCGGCTCT $\begin{array}{lllllllllllllllllllll}\mathbf{L} & \mathbf{P} & \mathbf{G} & \mathbf{L} & \mathbf{K} & \mathbf{K} & \mathbf{I} & \mathbf{G} & \mathbf{I} & \mathbf{S} & \mathbf{S} & \mathbf{V} & \mathbf{L} & \mathbf{L} & \mathbf{R} & \mathbf{K} & \mathbf{I} & \mathbf{I} & \mathbf{G} & \mathbf{S}\end{array}$ 211 CTGGAGGTGGGCTGCGGTGTGGTGCTCACCCTGGTGCCTGGCCGGCCGAAGGACGTGGCC $\begin{array}{llllllllllllllllllllll}\mathbf{L} & \mathbf{E} & \mathbf{V} & \mathbf{G} & \mathbf{C} & \mathbf{G} & \mathbf{V} & \mathbf{V} & \mathbf{L} & \mathbf{T} & \mathbf{L} & \mathbf{V} & \mathbf{P} & \mathbf{G} & \mathbf{R} & \mathbf{P} & \mathbf{K} & \mathbf{D} & \mathbf{V} & \mathbf{A} & 90\end{array}$ 271 AACTTTTTGCTGCTGCTGGTCATGCTGGCCGTCCTGTTCTTCCACCAGCTAGTGGGAGAC $\begin{array}{lllllllllllllllllllllll}\mathbf{N} & \mathbf{F} & \mathbf{L} & \mathbf{L} & \mathbf{L} & \mathbf{L} & \mathbf{V} & \mathbf{M} & \mathbf{L} & \mathbf{A} & \mathbf{V} & \mathbf{L} & \mathbf{F} & \mathbf{F} & \mathbf{H} & \mathbf{Q} & \mathbf{L} & \mathbf{V} & \mathbf{G} & \mathbf{D} & 110\end{array}$ Domain III 331 CCCCTGAAGCGGTACGCCCACGCTCTGGTCTTTGGCATCCTGCTCACCTGCCGGCTGCTC $\begin{array}{lllllllllllllllllllll}\mathbf{P} & \mathbf{L} & \mathbf{K} & \mathbf{R} & \mathbf{Y} & \mathbf{A} & \mathbf{H} & \mathbf{A} & \mathbf{L} & \mathbf{V} & \mathbf{F} & \mathbf{G} & \mathbf{I} & \mathbf{L} & \mathbf{L} & \mathbf{T} & \mathbf{C} & \mathbf{R} & \mathbf{L} & \mathbf{L} & 130\end{array}$ 391 ATCGCCCGCCAGACCGACGACCGGCCGGAGAGAGAGGACAGCAGAGAGGACAGCAGGTG $\begin{array}{lllllllllllllllllllll} & \mathbf{A} & \mathbf{R} & \mathbf{Q} & \mathbf{T} & \mathbf{D} & \mathbf{D} & \mathbf{R} & \mathbf{P} & \mathbf{E} & \mathbf{R} & \mathbf{E} & \mathbf{D} & \mathbf{S} & \mathbf{R} & \mathbf{E} & \mathbf{E} & \mathbf{Q} & \mathbf{Q} & \mathbf{V} & 150\end{array}$ 451 AACGACCAGGAAAAGAACAAGGTCAAGCAGTCCTAAga c c c t c tgc cact c tgg t c caa

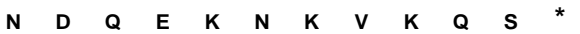

$511 \mathrm{gcc}$ acaggaatgggaaactgaagcgcct t atggattgtagtaat t tgaat t t gaagga 571 a c c g cactcc cagtaataaaaccctcacacatcc c c c gtctcatccaggtggctga $631 \mathrm{ctgaataccctcaccc}$ actcctctgcaccattaatgtgaaccaagaaccctgatccat $631 \mathrm{ctgaataccctcacccactcctctgcaccattaatgtgaaaccaagaacccctgatccat}$
$691 \mathrm{acgtcctctacataaacatggacaatcttacctttggaaactctgaagagctcagctcgc}$

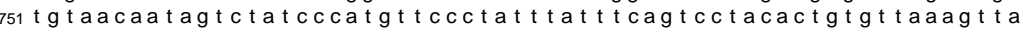

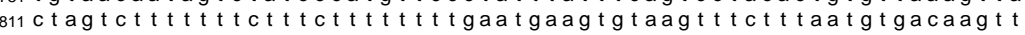
$871 \mathrm{gat} t \mathrm{tgagaatgctgtt} \mathrm{t} \mathrm{tcatgaaagaatct} \mathrm{t} \mathrm{tg} \mathrm{tagct} \mathrm{tg} \mathrm{t} \mathrm{t} \mathrm{t} \mathrm{t} \mathrm{t} \mathrm{c} \mathrm{taat} \mathrm{t} \mathrm{tg} t \mathrm{t}$ $931 \mathrm{t} \mathrm{tatactgtatgtaggagagactggtaatt} \mathrm{tatgaat} \mathrm{t} \mathrm{caat} \mathrm{a} \mathrm{t} \mathrm{t} \mathrm{c} \mathrm{a} \mathrm{a} \mathrm{c} \mathrm{a} \mathrm{t} \mathrm{g} \mathrm{t} \mathrm{t} \mathrm{ca}$ $991 \mathrm{tctggtcaagacaacagaacataaagcaaaccgagcactgctgaaaggttttgtactaa}$ 1051 c c a c c a t acat t aggaagt at t act a agccgcatct gact t tgat gcaat 1111 agg ct at t t a a a tga 1111 t t $1231 \mathrm{ctcctt} t \mathrm{tagtt} c a g t g a a c a c a g t g a a g t t g t t a a g c t g g g g a a g g a c c g c a g c t t c t g$ $1291 \mathrm{cct}$ caggtg t c tgctgcctactcgtacagctgaacatccagctcagtct t t tg t c cgt t 1351 aaat tgagct tgact t t g t t t t t t a a t cacagt t t aggat tat t c t c tg t c t c g 1411 a a a cggctctgct caacc t t ggtt t aacgtt t c c tctg taagat t t aatatcct

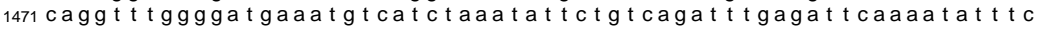
$1531 \mathrm{tgtaa} t g a t a t a c t t c a a \operatorname{aaagaat} t g g a \operatorname{tatgactggca}$

B

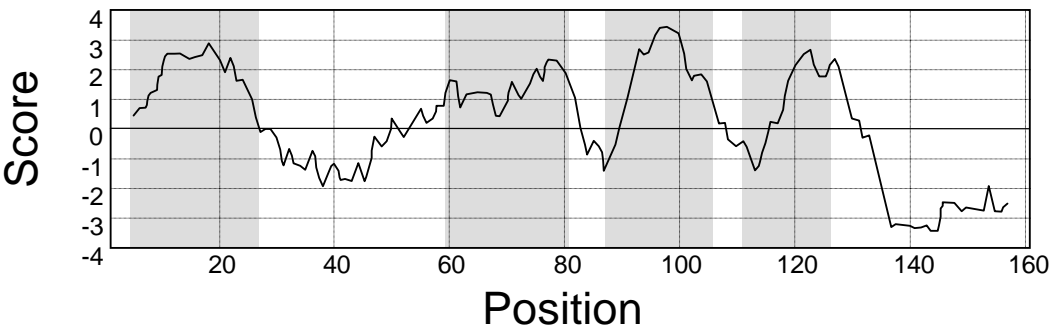

Fig. 1. (A) Nucleotide and deduced amino acid sequences of flounder Xp18. The open reading frame is indicated in capital letters. The two polyadenylation/cleavage sites are underlined. The deduced peptide sequence is represented with the one letter code for amino acids. The anchor domain to the ER is indicated in gray and the three other putative transmembrane domains are boxed in black. The TAA stop codon is marked by a star. Circles and diamonds respectively indicate putative phosphorylation and N-myristoylation sites. (B) Hydrophobicity profile of flounder Xp18 protein (Kyte and Doolittle, 1982). Amino acids are numbered from the translation start site. The four putative transmembrane domains are shaded. 


\subsection{Comparison of Xp18 orthologuous sequences}

Searches in nucleotide databases revealed that the Xp18 cDNA clone had a high degree of homology with a human cDNA sequenced from whole embryos (Isogai et al., 2000) and with Expressed Sequence Tags obtained from the brain of Rattus norvegicus (Bonaldo et al., 1996), Mus musculus (Bonaldo et al., 1996, Sasaki et al., 1998) and Brachydanio rerio (Clark et al., 2001), as well as from lymphoid organs of Bos taurus (Smith et al., 2000) and Gallus gallus (Tirunagaru et al., 2000). Comparison of the deduced amino acid sequences from flounder and human cDNAs, zebrafish, mouse, rat, bovine and chicken ESTs revealed a high level of conservation during evolution (Fig. 2A and 2B). Amino acid identity of Flounder Xp18 reached 96\%,83\%,81\% and 82\% with, respectively, zebrafish, bovine, mouse and human polypeptides. The amino-terminus and the core of the proteins were almost perfectly conserved whereas the last 30 amino acids of the carboxy-terminus were much more divergent. Putative transmembrane segments appeared to be conserved including the anchor signal. Such a high degree of conservation suggests that Xp18 protein plays an important functional role. A substantial identity (38\%) was also observed with a 160 amino acid product of a recently identified gene in the fruit fly, Drosophila melanogaster (Adams et al., 2000). However, the fruit fly protein lacked the characteristic KVKXS motif present at the Cterminus end of all vertebrate Xp18 proteins. Extensive Blast and Fasta searches in genome databases did not allow the identification of Xp18 related polypeptides in prokaryotes, in yeast, or in the nematode Caenorhabditis elegans. 


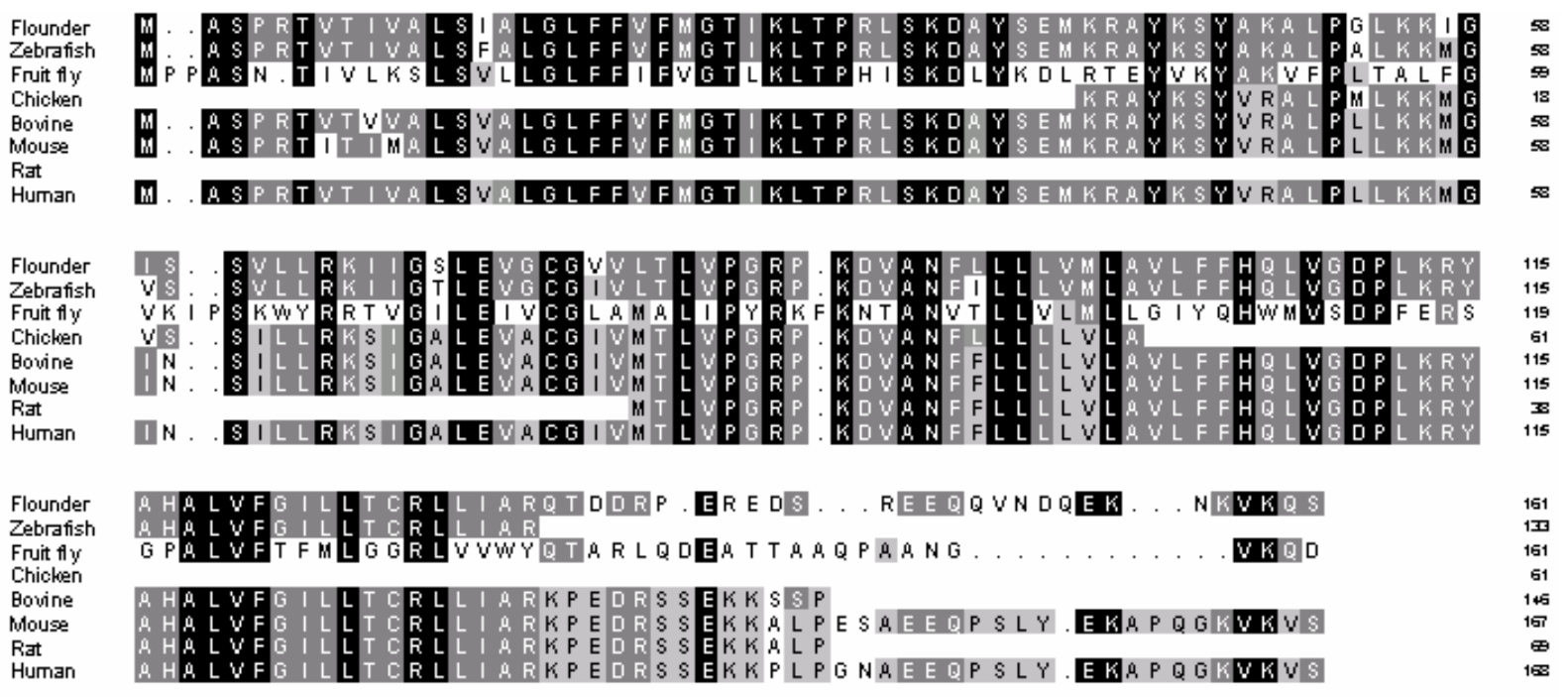

A

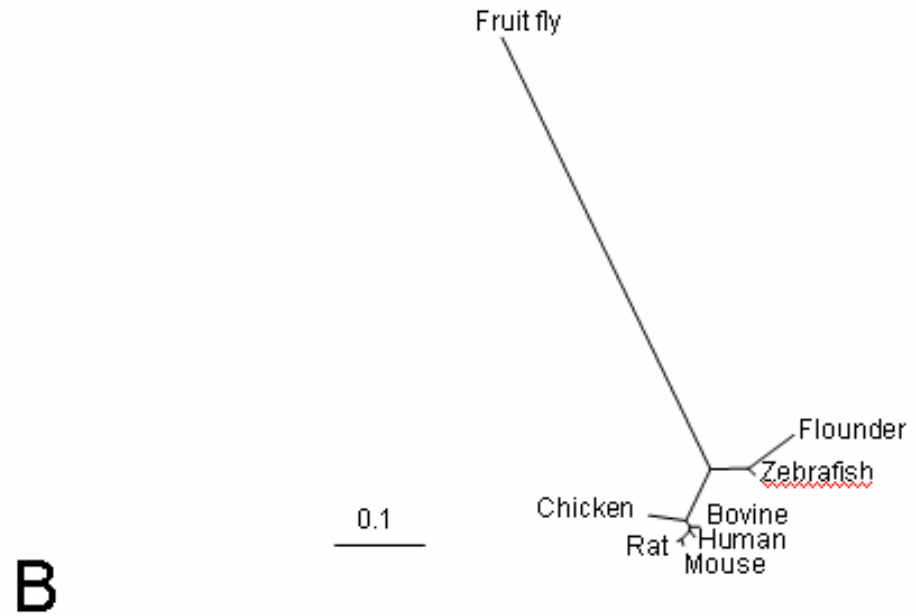

Fig. 2. (A) Sequence alignment of flounder Xp18 deduced protein with zebrafish (Clark et al., 2002), fruit fly ( Adams et al., 2000), chicken ( Tirunagaru et al., 2000), bovine ( Smith et al., 2000 modified), mouse ( Bonaldo et al., 1996 and Sasaki et al., 1998), rat ( Bonaldo et al., 1996), and human ( Isogai et al., 2000) homologues. Multiple alignment was calculated by using ClustalW software ( Thompson et al., 1994) and corrected manually. Residues conserved in all species in which the sequence is known are boxed in black. Residues common to flounder and to any other species are shaded in gray. Amino acids common to at least half of the known sequences are shown in light gray background. (B) Cladogramme of Xp18 proteins as calculated from the multiple alignment. Bar corresponds to 0.1 residue substitutions per site.

In silico screening of genome databases with flounder Xp18 cDNA sequence revealed that the human and mouse Xp18 genes were located on the X chromosome (Sanger Centre, 2002). The human homologue was mapped to Xq22.1, a region implicated in several genetic diseases (OMIM, 2002), including premature ovarian failure (Bione et al., 1998). The human and the mouse Xp18 genes as were organized as two exons separated by a large intron. The exon-intron boundaries were perfectly conserved between the two species. Exon 1 encoded the first 40 amino acids of the protein while the second exon encoded the last 127 residues. Analysis of the 2,500 bp sequence located upstream from the initiation codon revealed the 
presence of multiple potential recognition sites for transcription factors including several putative binding sites for the ubiquitous transcription factor Sp1. The presumed promotor region also contained putative binding sites for the estrogen receptor, Hepatocyte Nuclear Factor-1, MyoD and Nuclear Factor Kappa B. The presence of a potentially functional estrogen responsive element within the promoter region is of particular interest with respect to the high expression of Xp18 in the fish ovary.

\subsection{Xp18 expression profile in flounder}

Northern blot analysis revealed a strong expression of a single transcript in the ovary. A medium Xp18 expression was also found in the brain of flounder. No hybridization signal was detected in the other tissues tested (Fig. 3). The transcript was about $1650 \mathrm{bp}$ in length and thus may represent a mature form of the mRNA. Quantitative RT-PCR analysis allowed detection of a basal Xp18 expression in all tissues tested. However important differences among tissues were measured. A statistically significant higher level of Xp18 expression was shown in the ovary in comparison with the brain $(P=0.005)$ or in the latter in comparison with the testis $(P=0.056)$. No significant differences were observed between ovary of different developmental stages. In most tissues; e.g. testis, spleen, kidney, gill, heart, intestine and liver, Xp18 was 10 to 100 fold less expressed than in the ovary (Table 1).

Table 1. LightCycler RT-PCR quantification of Xp18 to $\beta$-actin mRNA ratio in different flounder tissues

\begin{tabular}{|c|c|c|c|c|}
\hline Tissues & $\operatorname{Sex}$ & Number of individuals. & $\begin{array}{l}\text { Xp18 fo B-actin mRNA ra } \\
\text { lio }(\text { mean }+S D)\end{array}$ & $P$ value $(f$-tesi $)$ \\
\hline Ovary & F & 6 & $0.789 \pm 0.427$ & \\
\hline Brain & $\mathrm{F}$ & 5 & $0.211 \pm 0.110$ & 0.005 \\
\hline Testis & M & 4 & $0.087 \pm 0.013$ & 0.056 \\
\hline Ovary stage $\Pi I$ & F & $3^{2}$ & $0,945 \pm 0,482$ & \\
\hline Oxary stage III and IV & F & $3^{2}$ & $0,488 \pm 0,220$ & 0,209 \\
\hline Brain of male & M & $2^{b}$ & $0,157 \pm 0,043$ & \\
\hline Muscle & F & $2^{b}$ & $0,157 \pm 0,083$ & \\
\hline Spleen & F & 2 & $0.077 \pm 0.033$ & \\
\hline Kidney & F & $2^{b}$ & $0,057 \pm 0,02$ & \\
\hline Gill & F & $?^{b}$ & $0.036 \pm 0,018$ & \\
\hline Heart & F & $2^{b}$ & $0,019 \pm 0,006$ & \\
\hline Intestine: & F & $2^{b}$ & $0.012 \pm 0.005$ & \\
\hline Liver & F & 2 & $0.010 \pm 0,006$ & \\
\hline
\end{tabular}




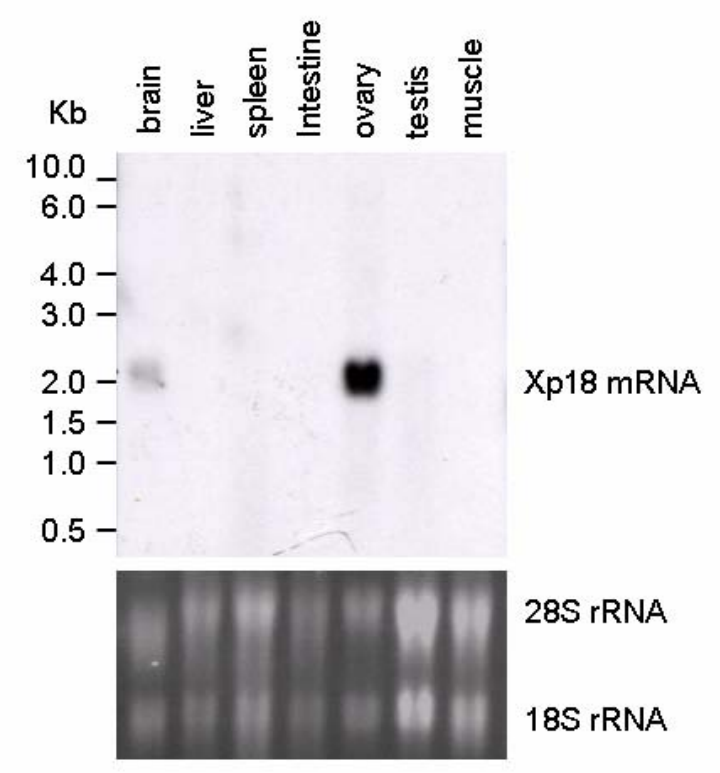

Fig. 3. Northern blot analysis of Xp18 mRNAs isolated from several tissues of adult flounders. A $\left(\alpha^{32} \mathrm{P}\right)$-dCTPlabeled fragment of flounder Xp18 cDNA was hybridized with $20 \mu \mathrm{g}$ of total RNA from flounder brain, liver, spleen, intestine, ovary, testis and muscle. Films were exposed for 14 days at $-80^{\circ} \mathrm{C}$ to X-ray films. To illustrate the uniformity of RNA loading, a picture of the ethidium bromide stained gel showing $18 \mathrm{~S}$ and $28 \mathrm{~S}$ ribosomal RNAs is shown below the Northern blot.
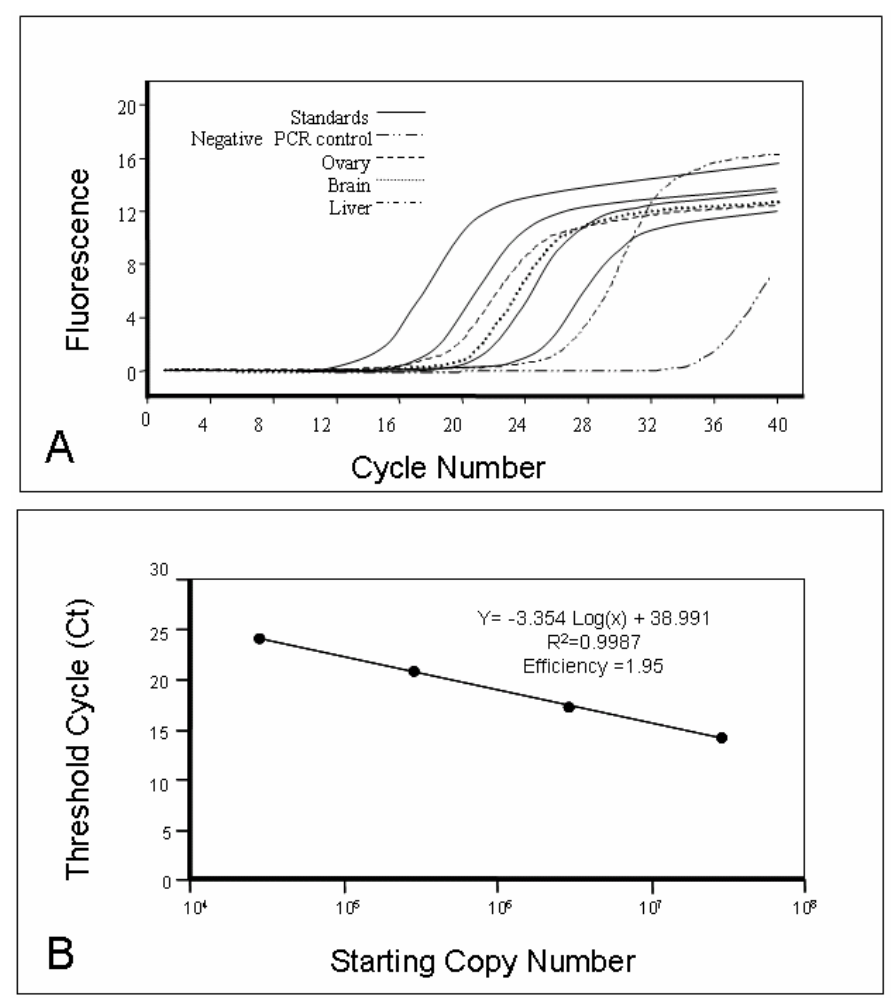

Fig. 4. Real time RT-PCR quantification of Xp18 and $\beta$-actin mRNA levels. Quantitative RT-PCR was performed with appropriate primers using LightCycler - FastStart DNA Master SYBR Green I dye (Roche Molecular Biochemicals). (A) Representative amplification plot of standards and samples; and (B) deduced standard curve for Xp18. Ct represents the threshold cycle at which fluorescence is first detected above background. A primer dimer signal was detected in the PCR negative control. 


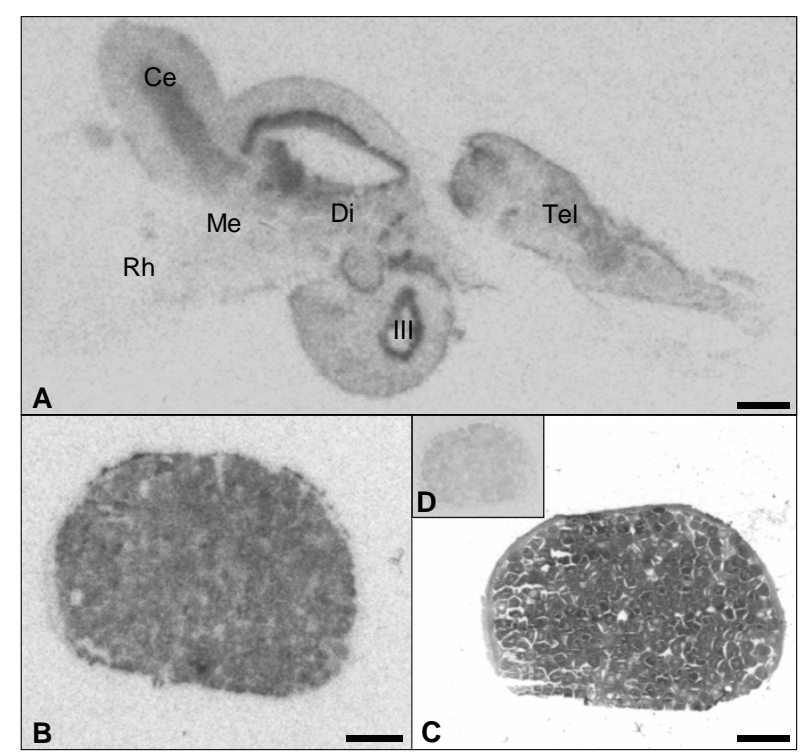

Fig. 5. Expression of Xp18 gene in the fish brain and ovary. (A) Parasagittal section of the fish brain illustrating the localization of Xp18 gene expression (Tel, telencephalon; Di: diencephalon; Me, mesencephalon; Ce, cerebellum; Rh, rhombencephalon; III, third ventricle). (B) Autoradiogram of a sagittal section through the ovary of a sexually mature fish labelled by in situ hybridization. The signal was restricted to the oocytes and the nuclei did not appear to be labelled. (C) Section of a fish ovary showing the histological organization of the organ. (D) Autoradiogram of a sagittal control section through the fish ovary hybridized with a sense probe to Xp18. Bars represent $1 \mathrm{~mm}$.

In situ hybridization (Fig. 5) revealed that the Xp18 gene was expressed in discrete regions of the flounder brain. A high hybridization signal was visualized in the circumventricular areas of the fish brain especially in the diencephalon around the third ventricle and in the mesencephalon around the tectal ventricle. In addition, a medium labeling was observed in the palial areas of the telencephalon. In the metencephalon, Xp18 mRNAs were also detected in the most internal layers of the cerebellum. In gonads, a strong hybridization signal was evenly distributed throughout the ovary whereas only a very weak staining was detected in the testis. Since in sexually mature flounders, the ovary is almost exclusively composed of oocytes, the Xp18 mRNA probe probably labeled germinal cells.

Data from ESTs suggested that Xp18 was expressed in oocytes of Xenopus laevis (Clifton et al., 2001) and in whole embryo of Oryzias latipes (Kohara et al., 2001) or fetal pancreas of human (Melton et al., 2002) as well as in several tissues of adults, such as the pancreatic islet in human (Melton et al., 2002), the brain of rodents (Bonaldo et al., 1996, Sasaki et al., 1998) and Brachydanio rerio (Clark et al., 2002), and the lymphoid organs of Bos taurus (Smith et al., 2000) and Gallus gallus (Tirunagaru et al., 2000). All these tissues are characterized by an important protein synthesis and transport associated to endocrine activity and/or cell proliferation.

\subsection{Conclusion}

Our data indicate that the Xp18 protein identified in flounder has a particularly high level of expression in the ovary. Structural prediction analysis suggests that it may correspond to an integral protein with four transmembrane domains possibly located in the ER 
membrane. The biological role of this protein remains to be established. However, the marked expression observed in the ovary supports the view that Xp18 may be involved in specific biological pathways associated with reproduction in females. In fact, cytogenetic studies have defined the $\mathrm{X}$ human chromosome long arm region Xq13.3-q26, where the Xp18 gene is located, as a critical region for normal ovarian function (Therman et al., 1990). Among the syndromes which have been mapped to this region of the $\mathrm{X}$ chromosome, premature ovarian failure (POF) is a defect of ovarian development characterized by primary or secondary amenorrhea with elevated levels of serum gonadotropins or by early menopause. POF candidate genes seem to be involved in normal ovary development and/or oogenesis (Bione et al., 1998). It would thus be of interest to investigate the existence of mutations and/or chromosomal abnormalities within the Xp18 gene in patients suffering from syndromes associated to ovarian malfunction. In the flounder, in situ hybridization studies conducted in intersexed male specimens may provide valuable information concerning the molecular mechanisms underlying the de-differentiation phenomenon that leads to the formation of ovarian structures in the testis.

\section{Acknowledgements}

We wish to thank F. Charbonnier and G. Raux (INSERM EMI 9906) for their technical assistance. The authors are indebted to Drs. B. Gonzales and H. Vaudry (INSERM U413) for their generous help in the analysis of in situ hybridization data. We gratefully thank Dr. P. Saugier-Veber (INSERM EMI 9906) and Dawn Hallidy (University of Le Havre) for their useful suggestions and critical review of this manuscript. This work was financially supported by the Agence de l'Eau Seine-Normandie and the Région Haute-Normandie (France). 


\section{References}

Adams, M.D., Celniker, S.E., Holt, R.A. et al., 2000. The genome sequence of Drosophila melanogaster. Science 287, 2185-2195. TREMBL accession number Q9W0B4.

Altschul, S.F., Gish, W., Miller, W., Myers, E.W., Lipman, D.J., 1990. Basic local alignment search tool. J. Mol. Biol. 215, 403-410.

Argos, P., Rao, J.K., Hargrave, P.A., 1982. Structural prediction of membrane-bound proteins. Eur. J. Biochem. 128, 565-575.

Bione, S., Sala, C., Manzini, C., Arrigo, G., Zuffardi, O., Banfi, S., Borsani, G., Jonveaux, P., Philippe, C., Zuccotti, M., Ballabio, A., Toniolo, D., 1998. A human homologue of the Drosophila melanogaster diaphanous gene is disrupted in a patient with premature ovarian failure : evidence for conserved function in oogenesis and implications for human sterility. Am. J. Hum. Genet. 62, 533-541.

Bonaldo, M.F., Lennon, G., Soares, M.B., 1996. Normalization and subtraction : two approaches to facilitate gene discovery. Genome Res. 6, 791-806.

Cachot, J., Galgani, F., Vincent, F., 1998. cDNA cloning and expression analysis of flounder p53 tumour suppressor gene. Comp. Biochem. Physiol. B 121, 235-242. DDBJ/EMBL/GenBank databases accession number Y08919.

Clark, M., Johnson, S.L., Lehrach, H., et al., 2002. DDBJ/EMBL/GenBank databases accession number BI427901.

Clifton, S., Johnson, S.L., Blumberg, B., et al., 2001. DDBJ/EMBL/GenBank databases accession number BI314943.

Hong, W., 1996. In : Protein trafficking along the exocytotic pathway, signal-mediated ER localization, R.G. Landes Company, Georgetown, pp. 81-91.

Isogai, T., Ota, T., Hayashi, K., et al., 2000. DDBJ/EMBL/GenBank databases accession number AK024146.

Janssen, P.A.H., Lambert, J.G.D., Goos, H.J.Th., 1995. The annual ovarian cycle and the influence of pollution on vitellogenesis in the flounder, Pleuronectes flesus. J. Fish Biol. 47, 509-523.

Kohara, Y., Shin-i, T., Kimura, T., Narita, T., Jindo, T., Takeda, H., 2001. DDBJ/EMBL/GenBank databases accession number BJ001946.

Kyte, J., Doolittle, R.F., 1982. A simple method for displaying the hydropathic character of a protein. J. Mol. Biol. 157, 105-132.

Lee, J.S., Franklin, T.M., Chipman, J.K., 2000. Cloning of the beta-actin gene from the European flounder. DNA Seq. 11, 83-86. DDBJ/EMBL/GenBank databases accession number AF135499.

Melton, D., Brown, J., Kenty, G., et al., 2002. DDBJ/EMBL/GenBank databases accession number BQ631899.

Minier, C., Levy, F., Rabel, D., Bocquené, G., Godefroy, D., Burgeot, T., Leboulenger, F., 2000. Flounder health status in the Seine Bay. A multibiomarker study. Mar. Environ. Res. 50, 373-377.

Nielsen, H., Engelbrecht, J., Brunak, S., von Heijne, G., 1997. Identification of prokaryotic and eukaryotic signal peptides and prediction of their cleavage sites. Protein Eng. 10, 1-6.

Nilsson, T., Jackson, M., Peterson, P.A., 1987. Short cytoplasmic sequences serve as retention signals for transmembrane proteins in the endoplasmic reticulum. Cell 58, 707-718.

OMIM, 2002. Online Medelian Inheritancein Man. http://www3.ncbi.nlm.nih.gov/Omim/

Pearson, W.R., Lipman, D.J., 1988. Improved tools for biological sequence comparison. Proc. Natl. Acad. Sci. USA 85, 2444-2448.

Rost, B., Sander, C., 1994. Combining evolutionary information and neural networks to predict protein secondary structure. Proteins 19, 55-72. 
Sanger Centre, 2002. These sequence data were produced by the Human Chromosome X Sequencing Group at the Sanger Centre and can be obtained from $\mathrm{fttp}: / /$ webace.sanger.ac.uk/cgi-bin/webace

Sasaki, Z., Suzuki, Y., Watanabe, M., et al., 1998. DDBJ/EMBL/GenBank databases accession number AU035365.

Smith, T.P.L., Casas, E., Stone, R.T., et al., 2000. DDBJ/EMBL/GenBank databases accession number BE808290 modified.

Therman, E., Laxova, R., Susman, B., 1990. The critical region on the human Xq. Hum. Genet. 85, 455-461.

Thompson, J.D., Higgins, D.G., Gibson, T.J., 1994. CLUSTAL W : improving the sensitivity of progressive multiple sequence alignment through sequence weighting, position-specific gap penalties and weight matrix choice. Nucleic Acids Res. 22, 4673-4680.

Tirunagaru, V.G., Sofer, L., Cui, J., Burnside, J., 2000. An expressed sequence tag database of T-cell-enriched activated chicken splenocytes : sequence analysis of 5251 clones. Genomics 66, 144-151.

Vethaak, A.D., Jol, J.G., 1996. Diseases of flounder Platichthys flesus in Dutch coastal and estuarines waters, with particular reference to environmental stress factors. I. Epizootiology of gross lesions. Dis. Aquat. Org. 26, 81-97. 